\title{
Uncertainty and monetary policy*
}

\author{
David Mayes \\ University of Auckland \\ Alberto Montagnoli \\ University of Stirling
}

January 2011

\begin{abstract}
Using the minutes of decision-,making committee meetings we analyse how the Bank of England, the Czech National Bank and the Sveriges Riksbank communicate uncertainty in their discussion of the setting of a forward-looking monetary policy. The aim is to test whether information about uncertainty in the minutes helps explain interest rate settings. We find that to show the effect of uncertainty it needs to be clear what the uncertainty is about, output or inflation for example. We also show that there is a relationship between the level of uncertainty expressed and the degree of disagreement in the committees.
\end{abstract}

JEL classification: E43, E52, E58

Keywords: communication, monetary policy, uncertainty, Taylor rule, Bank of England, Czech National Bank, Riksbank

\footnotetext{
* We thank Petra Geraats and Cris Shore for detailed comments and Charlie Fahy for research assistance. We are also grateful to the participants at the seminar at the Europe Institute, University of Auckland at the workshop Central Bank Communication, Decision-Making and Governance for comments and discussions. Montagnoli gratefully acknowledges financial support from the Europe Institute, University of Auckland.
} 


\section{Introduction}

There has been growing interest in uncertainty in monetary policy-making, and in the communication of monetary policy. There are many sides to the problem, starting simply with the fact that the future is uncertain. Also central banks in particular (notably the ECB, the Bank of England and the US Fed) have sponsored research into model uncertainty. ${ }^{2}$ Attention has also been paid to the uncertainty faced by markets to which central banks can contribute by erratic or unclear decision making. This has raised the importance of transparency on the part of the central bank (e.g. Eusepi, 2005). The main conclusion in the literature is that central bank transparency renders 'the optimal policy rule robust to expectational mistakes, even in the plausible case where the economic agents face other sources of uncertainty about the economic environment. On the other end, lack of transparency can lead to a welfarereducing outcome where self-fulfilling expectations destabilize the economic system' (Eusepi, 2005, p. 22). Similarly Mishkin (2004) argues that inflation targeting in particular is made more effective by transparency. Thus the message is that, whatever the sources of uncertainty, the central bank should not add to them.

Yet there have been dissenting voices on the unambiguous benefits of transparency, as Geraats (2002) shows in her survey article. Where the central bank is itself uncertain over the appropriate action, transparency which communicates that uncertainty could make monetary policy less effective. This issue is most relevant where this uncertainty is understood as being distinct from quantifiable risk, i.e. as reflecting the need for decision-makers to go beyond any one model and exercise judgement (Dow 2003).

A large body of researchhas sought to derive models of optimal monetary policy (e.g. to derive optimal Taylor-type rules) in the presence of uncertainty. The majority of the results adhere to the Brainard (1967) principle of conservatism or gradualism, that is a central bank is unsure about the magnitude and the nature of the economic effect on change in its instrument, it should change that instrument less than it would were it sure. ${ }^{3}$ Within a Taylor rule context, the theoretical literature ${ }^{4}$ has suggested two ways in which uncertainty should be handled: first uncertainly lowers the weights on output gap and inflation but does not have a direct effect on the interest rate. Second uncertainty regarding one variable (e.g. inflation)

\footnotetext{
${ }^{2}$ Uncertainty as to the preferred model on which policy is to be based.

${ }^{3}$ These results relate to what is known as additive uncertainty, i.e. uncertainty in addition to what is known. Where there is uncertainty about parameters in a model, the uncertainty is 'multiplicative' and the conclusion may not be so straightforward.

${ }^{4}$ see e.g. Peersman and Smets (1999), Walsh (2003) Swanson (2004).
} 
should increase the weight put on the other (e.g. output gap). ${ }^{5}$ Using data for the US, Martin and Milas (2008) find support for these theoretical predictions.

Matching the work on uncertainty, a new literature has been emerging which takes the issue of central bank communication seriously. This literature is based on the view that monetary policy consists not just of an interest rate decision and its communication, but also of communicating the analysis of the central bank, its expectations, and the confidence with which these are held. This wider communication is effected through press conferences and published documents, as well as different measures such as the central banks' fan charts that try to make the concepts and judgements clear. Thus Cobham (2003) and Dow et al. (2009) have provided a textual analysis of UK monetary policy committee minutes, while Rosa and Verga (2005a, 2005b) have analysed ECB press conference transcripts, to explain how such communication is used.

The methodology that we apply in this article builds on Dow et al. (2009) and Rosa and Verga (2005a) in particular. We analyze the semantic context of the minutes of the Monetary Policy Committee (MPC) of the Bank of England, the Executive Board (EB) of the Riksbank and of the Bank Board (BB) of the Czech National Bank; more specifically we contextualize the use of the word 'uncertainty' so that we can build a glossary to translate the language used in the minutes into quantitative variables. ${ }^{6}$ This allows us to capture the degree of uncertainty surrounding the meetings. Moreover, the index should capture the weight and the context in which the policymakers refer to the concept of uncertainty.

Our analysis allows comparison with previous research on other central banks; by studying the language used by central banks with respect to uncertainty in a way where the banks can be compared. Hence our aim is twofold: first we aim to derive indicators reflecting the uncertainty faced by the policymakers in their considerations. ${ }^{7}$ More specifically, after having constructed the uncertainty indexes, we investigate whether they have any particular role in the settings of monetary policy. Then, we link the textual analysis to the actual policy implementation; we estimate a Taylor rule model in which the coefficients on inflation and output gap are functions of our measures and uncertainty. Additionally we explore the possibility that the direction of voting can be used as a measure of uncertainty faced by the

\footnotetext{
${ }^{5}$ There are two exceptions to this rule: the first applies in the case of imperfect or low credibility. The second case applies when the there is uncertainty surrounding the degree of inflation persistence. In both cases policymakers may find optimal to act more vigorously than it would have been optimal in a no-uncertainty scenario.

${ }^{6}$ These three banks are chosen simply because they offer the longest consistent sets of minutes of the inflation targeting central banks, where the votes of the members are also published.

${ }^{7}$ For the preliminary theoretical foundation see Dow et al. (2005)
} 
monetary policy committees. Since the policy decisions are taken collegially it is possible that each individual member has his/her own model or even when a single model prevails, the uncertainty surrounding it may be subjective to each member.

Hence we test whether this manifestation of uncertainty can explain the settings of the interest rate.

The remainder of the paper is structured as follows. The next section present the context of uncertainty in which central banks operate, Section 3 presents the methodology used to construct the uncertainty indexes, Section 4 contains the econometric methodology, Section 5 discusses the results, Section 6 presents a discussion of uncertainty and committee dispersion, and Section 7 concludes.

\section{Nature of Uncertainty in monetary policy}

Monetary policy operates in conditions of uncertainty about the future and also in terms of a potential asymmetry between the knowledge of the monetary authority and market participants. Dow et al. (2007, 2009) define three sources of uncertainty; first is global uncertainty, which is a consequence of the stochastic nature of the economic environment. This also comprises uncertainty about the state of the economy, since there is imperfect information derived from the availability of data and the quality of the data themselves; some economic indicators are unobservable (e.g. the NAIRU, the potential output and the equilibrium rate of interest). Moreover the nature and the persistence of the shock are frequently unknown.

The second type of uncertainty is model uncertainty; even in a deterministic world, there is the possibility that our limited knowledge would not allow us to reach a single trusted model. While it would ease analysis of the problem if somehow the knowledge base of the central bank could be represented by a single definable and describable entity, policy decisions are usually taken by a committee, whose members have a diverse background, each with their own views on how the economy works and what may happen. Even though in a formal context central banks may have a formal model that they use in forecasting and explanation, 
they at the very least augment it with a range of other models, so there can be no exact exposition of the opinion forming process. ${ }^{8}$

A third type of uncertainty is signal uncertainty. Monetary policy is conducted not only via a change in the short term interest rate, but also through the revalation of the analysis and the motivation behind that particular value. This component is, probably, of central importance for a successful monetary policy, since the interest rate change itself appears to have little impact on future inflation and economic activity. This is largely because, as Svensson (2005) highlights, a successful policy maker is able to influence private sector inflation expectations. These expectations have a direct impact on the yield curve and on the long-term interest rate, which in turn will determine the path of current and future consumption and investment. In this framework, central bank communication leaves room for interpretation. Agents therefore have to make judgments about the implications, thereby adding uncertainty which may also be asymmetric in nature. This could make central bank transparency a two-edged sword. If the private sector understands the uncertainty facing the central bank better, this may in turn lead to less well anchored inflation expectations in the private sector if it previously thought there was less uncertainty. While anchoring expectations on the central bank's target is beneficial for effective policy, having the anchor through spuriously based certainty is a potential threat to future stability and effectiveness of policy should the weakness be realized. Something that is most likely to happen when the economy and monetary policy are under stress.

Central banks are likely to have better resources to form a view about likely inflation developmentsand how they might be influenced than most others in either the public or private sectors since this is their primary focus while others have broader concerns. While they will have a good understanding of the limitations of their knowledge outsiders will neither know what that knowledge is nor the degree of certainty with which it is held. However, the ability to communicate is also imperfect and there is hence a clear incentive to be clear rather than complete in putting the message across in the event of difficulty. There is further interdependence between the monetary authority's knowledge, and uncertainty, and those of the private sector, in that each forms expectations of what the other is likely to do both in the light of their own knowledge and their understanding of the other. As Issing (2005) reminds us 'data are often not self-explanatory, as their information content changes depending on the way they are communicated by the sender' (p.67).

\footnotetext{
${ }^{8}$ Even in cases, such as New Zealand, where a single individual, the Governor, decides, the degree of 'soft' information employed in decision making would make it unrealistic to use a single model to represent even the most systematic individual precisely.
} 
Moreover since the information provided by the central bank on its decision making process is both quantitative and discursive, information uncertainty has both quantifiable and non quantifiable aspects.

Although institutionalised procedures ultimately result in specific interest rate decisions, they are nevertheless open to different interpretations by market participants. It is this context which sets the scene for current debates on the transparency of central bank policies (e.g. Geraats 2002). The challenge for a policy committed to transparency consists in ensuring adequate transparency of the form and content of decision procedures for revealing the collective judgement of the decision-making body as well as sometimes revealing difference of opinion. ${ }^{9}$ This form of transparency should make it more likely that market behaviour is conditioned by the same expectations as the Central Bank, helping to improve the policy makers' ability to predict. But it also facilitates a closer anticipation of future decisions if the past decision process is well understood and procedures clearly follow a consistent pattern. Hence, these signals play a central role in monetary policy. The channels through which these signals are formed, are therefore of key importance in the success of the enterprise.

Therefore the central banks under investigation here follow an inflation targeting strategy; they all make decisions by committee and publish minutes that reveal internal differences of opinion. This comparative study allows some assessment of uncertainty as emerging from the minutes and how the voting dispersion shapes monetary policy.

Many central banks including those in this study make a very clear distinction between uncertainty and risk, very much along the lines of Knight (1921) and Keynes (1921) namely, between sources of variation that can be quantified and those that cannot. The use of fan charts typifies the view that it is the distribution of possible outcomes that is more valuable to the reader and more realistic for the forecaster - point estimates are always highly likely to be wrong and convey only limited information. The distribution of possible outcomes is a function of the probability distribution of shocks that can strike the economy over the forecast period. ${ }^{10}$

\footnotetext{
${ }^{9}$ Geraats (2002) makes it clear that there is a range is aspects over which central banks try to be transparent.

${ }^{10}$ Some central banks have described this more in terms of the distribution of errors that they typically make in forecasting and this is of course correct as the processes they use to decide how known and unknown events will affect future outcomes are themselves inevitably flawed as even after the event it is not possible to observe a pure shock and its outcome.
} 
If the central bank had no view at all about the factors that might impinge on the economy then fan charts would always be symmetric and risk and uncertainty would be lumped together in the probability distribution. In practice, however, there is a list of possible events that may occur that are obvious from recent developments. These may relate to policy changes for example. In these circumstances the distribution of likely outcomes may no longer be simply Normal and hence central banks produce a skewed distribution for forecasts depending on the balance of risk. ${ }^{11}$ In these circumstances the usual procedure is simply to add a third moment to the forecast distribution in order to describe the skew. This is a highly simplified procedure, reflecting the softness of the information and how it can be handled. It is, however, noteworthy that in many other circumstances, such as the mainstream finance literature, risk is usually described by variance. When central banks discuss risk they are normally discussing whether there are grounds for being able to talk about higher moments. In the face of crises for example, kurtosis may also enter the discussion, as the chance of a 'fat tail' on the downside increases, although the word itself is not likely to be used in describing the problem.

The idea that risk can be quantified and that many forces affecting the economy can be translated into a skew is common practice (Britton et al, 1998) even including the ECB, which signals the imprecision of point estimates by quoting a range rather than a point estimate. Nevertheless in the same way that assuming a Normal distribution measures the likely distribution of outcomes, assuming that adding the third moment captures risks is simplistic.

Risks are therefore normally discussed in an explicit section of monetary policy reports and may be either explicitly incorporated into the forecast or expressed in terms of scenarios. In the former case this represents a judgement on the balance of risks whereas in the latter case it is an illustration of the impact of specific alternative set of assumptions that reflect the materialisation of a specific risk or set of risks. Uncertainty on the other hand tends to be treated much more generally and relates to the confidence with which the various statements made in the text can be substantiated. This may relate even to the discussion of risks.

\section{Methodology}

Our basic premise here is that while uncertainty as such is unquantifiable in any cardinal way, it is still possible to identify evidence of more or less uncertainty, even

\footnotetext{
${ }^{11}$ Blix and Sellin (1999) discusses the case where both upside and downside risks may be normally distributed but with different variances. Adding such distributions will generate the skew.
} 
if such uncertainty can at best be partially ranked in an ordinal sense. This suggests broadening the range of economic data to include semantic information as well, and recent literature on central bank communication has done just that, by seeking to translate discursive information such as minutes of central bank committees and press releases into indicators of economic risk and uncertainty. Rosa and Verga (2005a, 2005b) analysing the ECB President's monthly conference, build an index which gives 'summary statistics of the ECB Governing Council view about both the future prospect of inflation and real activity in the Euro area'. On the most basic level, a simple count of uses of the terms 'uncertain' and 'uncertainty' can be taken as an ordinal indicator of how much uncertainty the central bank was experiencing.

Our focus is on the Bank of England, the Czech National Bank and the Sveriges Riksbank language on uncertainty in such a way as to allow some comparison with the previous studies. This should shed some light on the implications of the framework differences between the monetary authorities for communication about uncertainty, and how that relates to monetary policy decisions. Here the committee is treated as a single entity (i.e. voice) rather than a collection of individuals and a plurality of voices.

More specifically, we analyse the frequencies of the term 'uncertainty', studying how they are used in the minutes of the monetary policy committees without imposing our own interpretations. Since our focus is on how the MPC communicates its uncertainty we follow Dow et al. (2009) and we consider all word forms arising from the word stems 'uncertain'. This allows us to derive frequencies $f(U)$ which represent the number of times the respective set of expression $\mathrm{U}$ is instanced in a given $\mathrm{MPC} / \mathrm{EB} / \mathrm{BB}$ minute in a substantive way that reflects their assessment of uncertainty inherent in the given economic situation. To arrive at frequency counts that can be regarded as substantive in the sense described, raw counts of $U$ occurrences have to be subjected to a preliminary step of analysis that removes instances that merely arise as part of a conditional consideration in the minutes.

In each of our three cases we have sought to use the longest available database where monetary policy has been subject to the same (inflation targeting) regime. For the Bank of England we expand the database of Dow et al. (2009) from January 1999 to December 2007, for the CNB our sample starts on January 1999 and for the Riksbank our sample starts on February 2000. We have further recorded the length of each minute as a word count, to be 
able to control for possible change in length during particular months ${ }^{12} . L_{t}$ like $\mathrm{U}$ and $\mathrm{R}$ frequencies, disregards cover page and any annexes.

The derived frequency of uncertainty, $f(U)$, is then classified according the nature of the uncertainty described. Here we consider only two different subcategories: references to uncertainty on domestic inflation and uncertainty on economic/output activity/growth, which are main factors which could be considered to be of relevance when monetary policy decisions are taken. Table 1 presents a sample of the sentences that we consider in our indices. The data are derived from two independent passes over the minutes. The very few remaining disagreements were resolved by a third opinion.

\section{Empirical specification}

Our empirical analysis is based on the well-known Taylor rule (Taylor, 1993). It is widely accepted that the behaviour of the interest rate can be described by the following policy rule:

$i_{t}=a_{0}+a_{\pi}\left[E_{t} \pi_{t+n}-\pi *\right]+a_{y} y_{t}+\varepsilon_{t}$

Where $a_{0}$ is a constant, $i_{t}$ is the policy rate at time $t, E_{t} \pi_{t+1}$ is the expected level of inflation, $\pi *$ the targeted level of inflation and $y_{t}$ is the output gap. Allowing for interest rate smoothing, the above equation can be rewritten as:

$i_{t}=\left(1-\gamma_{t}\right) a_{0}+\gamma_{t} i_{t-1}+\left(1-\gamma_{t}\right)\left\{a_{\pi}\left[E_{t} \pi_{t+n}-\pi *\right]+a_{y} y_{t}\right\}+\xi_{t}$

Following the theoretical literature and Martin and Milas (2008) we know that the parameters, $a_{\pi}$ and $a_{y}$ are functions of uncertainty underlining the model and the state of the economy so that in presence of uncertainty the above equation can be rewritten as:

$i_{t}=\chi a_{0}+\left(\gamma_{t}+\gamma_{t}^{u n c} u_{t}\right) i_{t-1}+\chi\left\{\left(a_{\pi}+a_{\pi}^{u n c} u_{t}\right)\left[E_{t} \pi_{t+n}-\pi *\right]+\left(a_{y}+a_{y}^{u n c} u_{t}\right) y_{t}\right\}+\varsigma_{t}$

\footnotetext{
${ }^{12}$ For more details on the Bank of England see Dow et al.(2009).
} 
Where $\chi=\left(1-\gamma_{t}-\gamma_{t}^{u n c} u_{t}\right)$ and $u_{t}$ is the measure of uncertainty described in the previous section.

This method allows us to test whether the response to uncertainty as communicated in the central bank minutes is reflected in the behaviour of the policy makers that is whether in presence of uncertainty the interest rate settings adheres to the Brainard's principle. If the predictions of the theoretical literature are correct then we should expect $a_{\pi}^{\text {unc }}$ and $a_{y}^{\text {unc }}$ to take a value smaller than zero. On the other hand, $\gamma_{t}^{u n c}$ is expected to be positive since central bank may respond cautiously to uncertainty surrounding the data. ${ }^{13}$

Our second empirical specification considers the two sub-sets of uncertainty: inflation uncertainty and output uncertainty. Our second specification is therefore given by:

$i_{t}=\gamma_{t} i_{t-1}+\left(1-\gamma_{t}\right)\left\{a_{0}+\psi_{1}\left[E_{t} \pi_{t+n}-\pi *\right]+\psi_{2} y_{t}\right\}+\xi_{t}$

Where $\psi_{1}=\left(a_{\pi}+a_{\pi}^{\pi, \text { unc }} u_{t}^{\pi}+a_{\pi}^{y, \text { unc }} u_{t}^{y}\right)$ and $\psi_{2}=\left(a_{y}+a_{y}^{\pi, \text { unc }} u_{t}^{\pi}+a_{y}^{y, \text { unc }} u_{t}^{y}\right)$

Here $u_{t}^{\pi}$ and $u_{t}^{y}$ are inflation and output uncertainty, respectively. As state previously, the literature makes clear prediction of how an optimal policy should be set. If increased uncertainty leads to a more passive response to a variable and strengthen the response to the other we should expect $a_{\pi}^{\pi, u n c}<0$ and $a_{\pi}^{y, u n c}>0$ on the inflation side, while $a_{y}^{\pi, \text { unc }}>0$ and $a_{y}^{y, u n c}<0$ on the output.

\section{Empirical results}

In Table 2 through 4 we report the estimates for the various Taylor rule specifications. The sample period goes from 1999:1 to 2007:1 for the UK and the Czech Republic, while the sample starts in 2000 for Sweden. We use this sample period since we wanted to exclude from our analysis, the financial crisis, when monetary authorities were mainly focused on restoring financial stability and preventing the collapse of the financial system, rather than focusing on the more traditional objectives of inflation and output stabilization. For the interest rate we use the end of the month official bank rate, the forecasts of inflation are from the Bank of England Inflation Attitudes Survey,

\footnotetext{
${ }^{13}$ Orphanides (2008).
} 
from the CNB survery of Inflation expectations of households and the Economic Tendency Survey compiled by the National Institute of Economic Research for Sweden. ${ }^{14}$ The output gap is measured using the industrial production data detrended using the Hodrick-Prescott filter.

In column 1 of each table we report the estimates of traditional Taylor rules obtained from the generalized method of moments (GMM) estimation.

The estimates indicate that interest rates increase by more than two percentage points in response to a one percentage increase of point excess of inflation over the inflation target. The response to the output gap varies across our sample; we obtain a value of 0.931 as a response to a one percentage point excess of output over equilibrium output in Sweden against the 1.8 in the United Kingdom and a statistically insignificant response by the Czech National Bank. The intercept is statistically significant in all three cases and it is very close to the interest rate average for the sample period. The parameter $\gamma_{t}$ indicates that the interest rate is highly persistent, this is not surprising given the monthly series of the series and that central banks tend to adjust interest rate during months when the inflation report is published, which is when new information is available. ${ }^{15}$

Column (i) show the estimates of Taylor rules where all the parameters are allowed to be function of our measure of uncertainty. We find that uncertainty does not affect the interest rate smoothing parameter, $\gamma_{t}^{u n c}$. Hence we re-estimate the model setting $\gamma_{t}^{u n c}=0$.

The results using a single measure of uncertainty are not promising. The inclusion of measures of uncertainty does not support the prediction of the Brainard's principle. The estimates of the parameters of interest ( $a_{\pi}^{u n c}, a_{y}^{u n c}$ ) are of the opposite sign or not statistically different from zero. The reason for this could be twofold, either there is no valuable information about the uncertainty surrounding the policy decisions of the monetary policy committees or this measure of uncertainty is too general and hides the uncertainties which have a direct impact on the members of the policy committee. Hence, these results do not shed any light on which 'type' of uncertainty matters. The theoretical literature suggests that in the presence of uncertainty an optimal monetary policy should respond by decreasing the weight put on inflation when this indicator is uncertain, but it should increase the weight on

\footnotetext{
${ }^{14}$ With the expectation of Sweden where the forecast is available monthly, the quarterly observations are interpolated to obtain monthly series, as in Beasly et al. (2008).

${ }^{15}$ On this point see Cobham (2003).
} 
the other variables (in our case the output gap). To test this hypothesis we use our measure of inflation and output uncertainty. Results are presented in columns (iii).

The estimated coefficients of inflation and output uncertainty indicates that the response of interest rates to inflation is weaker when inflation is more uncertain and stronger when the output gap is more uncertain (although this latter effect is not statistically significant for Riksbank and the CNB). For the Bank of England we also find that the response to changes in output gap is affected by the two types of uncertainty, while for the Riksbank only inflation uncertainty is statistically significant.

As for inflation expectations, at the time monetary policy decisions are taken there is a high degree of uncertainty surrounding the output gap. To correct for this well known problem we use estimates of real time data for the output gap for Sweden and the UK as provided by the OECD output gap revisions database. ${ }^{16}$ The results presented in tables 6 and 7 seem to provide some support to the Brainard principle. The smaller response to inflation when inflation is less certain, while the larger response to inflation when output is less certain is consistent with the predictions of Peersman and Smets (1999) and Swanson (2004).

\section{Voting dispersion as a measure of uncertainty}

In this section we explore the link between the uncertainty as measured by the voting dispersion in the policy committees and the changes in the interest rate.

The rationality underlying a possible link between actual policy decisions and how members vote rests on the observation that policy committees are composed of members with different background. Recently a part of the literature has extensively investigated the implication of this diversity, suggesting the existence of heterogeneity across committee members with respect to information and preferences. For instance, studying the Bank of England, Gerlach-Kristen (2009) shows the existence of differences between internal and external members. Riboni and Ruge-Murcia (2008) and Besley, Meads, and Surico (2008) estimate individuals' Taylor rules; they suggest that long-run responses to the inflation gap are fairly homogenous, but individual characteristics are responsible for the heterogeneity in the MPC voting patterns.

\footnotetext{
${ }^{16}$ Data for the CNB are not available. The data are available at a quarterly frequency; hence the observations are interpolated to obtain monthly series.
} 
In this context, it is reasonable to assume that "each member of the monetary policy committee holds a particular view of the behaviour of the economy represented by a macro model" and with it comes a level of confidence or uncertainty, Levin and Williams (2003, p.946). Even if there is a single trusted model shared across the members, it is plausible that each member would attach an individual degree of uncertainty.

If this is the case, then each member's vote would adhere to the Brainard's principle of conservatism, and as a whole a high level of committee uncertainty would be reflected in a high level of voting dispersion.

We measure voting dispersion as:

Voting dispersion $=\frac{(\text { total number of votes }- \text { majority votes })}{(\text { number } \text { required for a majority }-1)}$

so that the variable runs from zero for full agreement to unity for the maximum level of disagreement possible.

In table 6 we re-estimate the model replacing the uncertainty measure with the level of voting dispersion. For all three central banks, there is no evidence that the voting dispersion has an impact on the interest rate smoothing; this is in accordance with the estimates obtained from our derived measure of uncertainty.

Looking first at the results from the CNB we notice that the estimates are very close to the one of the Taylor rule with no uncertainty, but there is no evidence that voting dispersion had any impact on the interest rate. Moving to the Riksbank, the results suggests that uncertainty as measured by the voting dispersion has no impact on the response of interest rate to inflation deviations from the target and the output gap. For the Bank of England estimates of uncertainty are statistically significant, at the usual level of confidence, but only the uncertainty surrounding inflation has the expected sign. 


\section{Conclusions}

In this paper we have derived three measures of uncertainty using the minutes of the committees of the Bank of England, the Czech National Bank and the Sveriges Riksbank.

We estimated the impact of uncertainty on monetary policy using the traditional Taylor rule framework. The foundation of this work rested on the theoretical literature which suggests that in the presence of uncertainty central bankers should lower the weights on output gap and on inflation but does not have a direct effect on the interest rate.

We have found some evidence that monetary policy has been affected by uncertainty and that these effects are generally consistent with the predictions of the theoretical literature. The predictions made by the literature are verified for the Riksbank and partly satisfied in the estimations of the Bank of England interest rate. However we find no role for uncertainty in the CNB. We find it difficult to believe that uncertainty has no place in the CNB committee, we can only conjecture that this lack of evidence rests on how the minutes are written.

Our work can be extended in a number of ways. This framework can be applied to other countries in order to test whether there is a clear pattern in the response of monetary policy to uncertainty and whether banks following an inflation targeting strategy behave differently from those that adopt other strategies. It would also be of interest to analyse the impact of financial market uncertainty and investigate if asset price uncertainty has had any impact on the monetary policy. Finally, there are manay more sophisticated forms of textual analysis that can be used. 


\section{References}

Brainard, W. (1967). "Uncertainty and the effectiveness of policy", American Economic Review, 57, 411-425.

Besley, T., N. Meads, and P. Surico (2008): "Insiders versus Outsiders in Monetary Policymaking”, American Economic Review: Papers \& Proceedings 98, 218-223.

Blix, M., and Sellin, P (1999), "Inflation Forecast with Uncertainty Bands", Quarterly Review, 2, Sveriges Riksbank.

Britton, E., Fisher, P. and Whitley, J. (1998). "The Inflation Report Projections: Understanding the Fan Chart", Bank nof England Quarterly Bulletin, February, pp.3037.

Cobham, D. (2003). "Why does the Monetary Policy Committee smooth interest rates?", Oxford Economic Papers, vol. 55(3), 467-93.

Dow, S C (2004) "Uncertainty and Monetary Policy, Oxford Economic Papers 56, 539-561.

Dow, S C, Klaes, M and Montagnoli, A. (2007). "Monetary Policy by Information" in D. G. Mayes and J Toporowski (eds.), Open Market Operations and the Financial Markets. London: Routledge.

Dow, S C, Klaes, M and Montagnoli, A., (2009). "Risk and Uncertainty in Central Bank Signals: An Analysis of the MPC Minutes", Metroeconomica Vol. 60(2), pp. 585-618

Eusepi, S. (2005). "Central bank transparency under model uncertainty", Staff Reports 199, Federal Reserve Bank of New York.

Geraats, P. M. (2002). “Central bank transparency”, Economic Journal 112 (483), F532-65.

Gerlach-Kristen, P. (2009). "Outsiders at the Bank of England's MPC", Journal of Money, Credit, and Banking 41, 1099-1115.

Hansen, L. P. and Sargent, T. J. (2004). Robust Control and Economic Model Uncertainty, Princeton, NJ: Princeton University Press.

Issing, O (2005) "Communication, Transparency, Accountability: Monetary Policy in the Twenty-First Century”, Federal Reserve Bank of St. Louis Review 87(2), 65-83.

Keynes J M. (1921/1973) A Treatise on Probability. Reprinted in Collected Writings of John Maynard Keynes 8, Macmillan, London, for the Royal Economic Society. 
Knight F H (1921) Risk, Uncertainty and Profit. Boston, MA: Hart, Schaffner \& Marx, Houghton Mifflin Company.

Martin, C. and Milas, C. (2009). "Uncertainty And Monetary Policy Rules In The United States", Economic Inquiry, Western Economic Association International, vol. 47(2), 206-215.

Mishkin, F. H. (2004). "Can central bank transparency go too far?" in Reserve Bank of Australia, NBER Working Paper, N.10829.

Orphanides, A. 1998. "Monetary Policy Evaluation With Noisy Information.” Federal Reserve Board. Finance and Economics Discussion Series, 1998-50.

Riboni, A. and F. J. Ruge-Murcia (2008). "Preference Heterogeneity in Monetary Policy Committees", International Journal of Central Banking 4, 213-233.

Rosa, C and Verga, G (2005a) "Is ECB Communication Effective?", CEP Discussion Paper No. 682.

Rosa, C and Verga, G (2005b) "The Importance of the Wording of the ECB", CEP Discussion Paper No. 694. 


\section{Appendix I}

Table 1: Sample of inflation uncertainty and output uncertainty

\begin{tabular}{|c|c|c|}
\hline & Inflation Uncertainty & Ouput uncertainty \\
\hline \multirow[t]{2}{*}{ Bank of England } & $\begin{array}{l}\text { The overall effect of the exchange } \\
\text { rate depreciation on inflation was } \\
\text { highly uncertain, especially if } \\
\text { overseas exporters' margins to the } \\
\text { UK fell more sharply than } \\
\text { previously expected and if retail } \\
\text { margins were squeezed further. } \\
\text { (June 2000) }\end{array}$ & $\begin{array}{l}\text { Second, there was uncertainty } \\
\text { about the estimate for GDP for } \\
\text { the first quarter. (June 2002) }\end{array}$ \\
\hline & $\begin{array}{l}\text { The short-term outlook for CPI } \\
\text { inflation was particularly } \\
\text { uncertain: it was unclear how } \\
\text { much of the recent rise in energy } \\
\text { prices had yet to pass through the } \\
\text { supply chain [...] (November } \\
\text { 2005) }\end{array}$ & $\begin{array}{l}\text { Overall, the near-term outlook for } \\
\text { output growth had probably } \\
\text { softened, but the extent of this } \\
\text { was uncertain. (October 2004) }\end{array}$ \\
\hline \multirow[t]{2}{*}{$\begin{array}{l}\text { Czech National } \\
\text { Bank }\end{array}$} & $\begin{array}{l}\text { In contrast, the future } \\
\text { development of demand inflation } \\
\text { would be affected by strong } \\
\text { uncertainties (downward in } \\
\text { nature) relating especially to } \\
\text { investment dynamics (February } \\
\text { 2001) }\end{array}$ & $\begin{array}{l}\text { Uncertainty concerning the } \\
\text { intensity of future economic } \\
\text { recovery [...] (March 2000) }\end{array}$ \\
\hline & $\begin{array}{l}\text { The quantification and timing of } \\
\text { these price effects constituted an } \\
\text { important uncertainty surrounding } \\
\text { the inflation forecast (September } \\
\text { 2002) }\end{array}$ & $\begin{array}{l}\text { It was also said that the revision } \\
\text { of the national accounts, which is } \\
\text { currently under way could } \\
\text { increase the uncertainty regarding } \\
\text { the past and present development } \\
\text { of GDP and the output gap (June } \\
\text { 2004) }\end{array}$ \\
\hline \multirow[t]{2}{*}{ Riksbank } & $\begin{array}{l}\text { The situation has changed a good } \\
\text { deal since the spring, when a } \\
\text { positive interest rate differential } \\
\text { with the European Central Bank's } \\
\text { rate was motivated by Sweden's } \\
\text { more expansionary fiscal policy, a } \\
\text { weak exchange rate and } \\
\text { uncertainty about the path of } \\
\text { domestic inflation. (October } \\
\text { 2002) }\end{array}$ & $\begin{array}{l}\text { The Executive Board concluded } \\
\text { that economic developments } \\
\text { continue to be marked by the } \\
\text { great uncertainty regarding the } \\
\text { Iraq crisis, the uncertainty } \\
\text { regarding the strength of } \\
\text { international economic activity } \\
\text { and increased savings resulting } \\
\text { from households' and companies' } \\
\text { balance sheets adjustments after } \\
\text { the fall in share prices (February } \\
\text { 2003) }\end{array}$ \\
\hline & $\begin{array}{l}\text { There was considerable } \\
\text { uncertainty over how lasting the } \\
\text { effects on inflation would be } \\
\text { (March 2005) }\end{array}$ & $\begin{array}{l}\text { The information received since } \\
\text { then had also to some extent } \\
\text { dispersed uncertainty over } \\
\text { economic activity in Sweden and } \\
\text { abroad, and the assessment was } \\
\text { that inflation would rise when } \\
\text { capacity utilisation increased. } \\
\text { (December 2005) }\end{array}$ \\
\hline
\end{tabular}

Notes: Date in parenthesis refers to the month the sentence appeared to. 
Table 2: Taylor rule estimates - Sweden

\begin{tabular}{|c|c|c|c|c|}
\hline & \multirow[t]{2}{*}{ Taylor rule } & \multicolumn{3}{|c|}{ Taylor rule with uncertainty } \\
\hline & & (i) & (iii) & (iii) \\
\hline$a_{0}$ & $2.934 * * *$ & $3.018 * * *$ & $2.781 * * *$ & $1.995 * * *$ \\
\hline$\gamma_{t}$ & $0.901 * * *$ & $0.880 * * *$ & $0.872 * * *$ & $0.970 * * *$ \\
\hline$\gamma_{t}^{u n c}$ & & -0.000 & & \\
\hline$a_{\pi}$ & $2.025 * * *$ & $2.372 * * *$ & $2.776 * * *$ & $2.903 * * *$ \\
\hline$a_{\pi}^{u n c}$ & & -0.000 & 0.000 & \\
\hline$a_{\pi}^{\pi, u n c}$ & & & & $-0.111 * * *$ \\
\hline$a_{\pi}^{y, u n c}$ & & & & $0.002 * * *$ \\
\hline$a_{y}$ & $0.795 * * *$ & $1.717 * * *$ & $1.549 * * *$ & $1.509 * * *$ \\
\hline$a_{y}^{u n c}$ & & 0.001 & $0.001 * *$ & \\
\hline$a_{y}^{y, u n c}$ & & & & $-0.015 * * *$ \\
\hline$a_{y}^{\pi, u n c}$ & & & & -0.001 \\
\hline J-stats & $15.40(\mathrm{p}=0.65)$ & $5.79(\mathrm{p}=0.44)$ & $4.62(p=0.70)$ & $4.41(\mathrm{p}=0.90)$ \\
\hline
\end{tabular}

Notes: The weight matrix is Heteroskedasticity- and autocorrelation-consistent. Standard errors robust to autocorrelation and heteroskedasticity. $*, * *, * * *$ denotes significance at 10, 5 and 1 level. J-stats refers to the Hansen's J statistics.

Table 3: Taylor rule estimates - UK

\begin{tabular}{|c|c|c|c|c|}
\hline & \multirow[t]{2}{*}{ Taylor rule } & \multicolumn{3}{|c|}{ Taylor rule with uncertainty } \\
\hline & & (i) & (ii) & (iii) \\
\hline$a_{0}$ & $4.128 * * *$ & $4.229 * * *$ & $4.209 * * *$ & $4.913 * * *$ \\
\hline$\gamma_{t}$ & $0.964 * * *$ & $0.944 * * *$ & $0.944 * * *$ & $0.932 * * *$ \\
\hline$\gamma_{t}^{u n c}$ & & -0.000 & & \\
\hline$a_{\pi}$ & $2.955 * * *$ & $1.812 * * *$ & $1.840 * * *$ & $2.147 * * *$ \\
\hline$a_{\pi}^{u n c}$ & & -0.006 & 0.007 & \\
\hline$a_{\pi}^{\pi, u n c}$ & & & & $-0.020 * *$ \\
\hline$a_{\pi}^{y, u n c}$ & & & & $0.177 * *$ \\
\hline$a_{y}$ & $1.880 * * *$ & $0.728 * *$ & $0.729 * * *$ & $0.176 * * *$ \\
\hline$a_{y}^{u n c}$ & & $-0.013 * *$ & $-0.013 * * *$ & \\
\hline$a_{y}^{y, u n c}$ & & & & $0.013 * * *$ \\
\hline$a_{y}^{\pi, u n c}$ & & & & $-0.035 * * *$ \\
\hline J-stats & $21.44(0.123)$ & $5.65(\mathrm{p}=0.91)$ & $5.649(\mathrm{p}=0.90)$ & $6.70(\mathrm{p}=0.80)$ \\
\hline
\end{tabular}

Notes: The weight matrix is Heteroskedasticity- and autocorrelation-consistent. Standard errors robust to autocorrelation and heteroskedasticity. $*, * *, * * *$ denotes significance at 10,5 and 1 level. J-stats refers to the Hansen's J statistics. 
Table 4: Taylor rule estimates - Czech Rebublic

\begin{tabular}{|c|c|c|c|c|}
\hline & \multirow[t]{2}{*}{ Taylor rule } & \multicolumn{3}{|c|}{ Taylor rule with uncertainty } \\
\hline & & (i) & (ii) & (iii) \\
\hline$a_{0}$ & $3.382 * * *$ & $2.706 * * *$ & $2.823 * * *$ & $4.491 * * *$ \\
\hline$\gamma_{t}$ & $0.960 * * *$ & $0.958 * * *$ & $0.956 * * *$ & $.961 * * *$ \\
\hline$\gamma_{t}^{u n c}$ & & 0.000 & & \\
\hline$a_{\pi}$ & $2.851 * * *$ & $3.538 * *$ & $3.780 * * *$ & $3.565 *$ \\
\hline$a_{\pi}^{u n c}$ & & $0.078 *$ & $0.090 * * *$ & \\
\hline$a_{\pi}^{\pi, u n c}$ & & & & $-0.019 * * *$ \\
\hline$a_{\pi}^{y, u n c}$ & & & & 0.027 \\
\hline$a_{y}$ & -0.109 & -0.450 & $-0.636 *$ & -0.425 \\
\hline$a_{y}^{u n c}$ & & -0.006 & $-0.019 *$ & \\
\hline$a_{y}^{y, u n c}$ & & & & 0.034 \\
\hline$a_{y}^{\pi, u n c}$ & & & & -0.005 \\
\hline J-stats & $1.45(\mathrm{p}=0.92)$ & $5.47(\mathrm{p}=0.90)$ & $4.78(\mathrm{p}=0.68)$ & $6.43(\mathrm{p}=0.59)$ \\
\hline
\end{tabular}

Notes: The weight matrix is Heteroskedasticity- and autocorrelation-consistent. Standard errors robust to autocorrelation and heteroskedasticity. $*, * *, * * *$ denotes significance at 10,5 and 1 level. J-stats refers to the Hansen's J statistics.

Table 5: Taylor rule estimates with voting dispersion

\begin{tabular}{c|ccc}
\hline & Riksbank & Bank of England & Czech National Bank \\
\hline$a_{0}$ & $3.285 * * *$ & $5.318 * * *$ & $3.138 * * *$ \\
$\gamma_{t}$ & $0.956 * * *$ & $0.965 * * *$ & $0.971 * * *$ \\
$\gamma_{t}^{u n c}$ & -0.007 & $-0.0002 * * *$ & $0 . .000$ \\
$a_{\pi}$ & $2.823 * * *$ & $2.210 * * *$ & $2.474 * * *$ \\
$a_{\pi}^{u n c}$ & $-0.174 * * *$ & $-0.018 * * *$ & -0.012 \\
$a_{y}$ & $0.445 * * *$ & $2.878 * * *$ & -0.613 \\
$a_{y}^{u n c}$ & $-0.034 * * *$ & $0.026 * * *$ & -0.028 \\
\hline & & & $5.45(\mathrm{p}=0.85)$ \\
\hline
\end{tabular}

Notes: The weight matrix is Heteroskedasticity- and autocorrelation-consistent. Standard errors robust to autocorrelation and heteroskedasticity. $*, * *, * * *$ denotes significance at 10,5 and 1 level. J-stats refers to the Hansen's J statistics. 


\section{Appendix II}

Table 6: Taylor rule estimates with real time data - Sweden

\begin{tabular}{|c|c|c|c|c|}
\hline & \multirow[t]{2}{*}{ Taylor rule } & \multicolumn{3}{|c|}{ Taylor rule with uncertainty } \\
\hline & & (i) & (iii) & (iii) \\
\hline$a_{0}$ & $2.934 * * *$ & $3.018 * * *$ & $2.781 * * *$ & $1.995 * * *$ \\
\hline$\gamma_{t}$ & $0.901 * * *$ & $0.880 * * *$ & $0.872 * * *$ & $0.924 * * *$ \\
\hline$\gamma_{t}^{u n c}$ & & -0.000 & & \\
\hline$a_{\pi}$ & $2.025 * * *$ & $2.372 * * *$ & $2.776 * * *$ & $2.903 * * *$ \\
\hline$a_{\pi}^{u n c}$ & & -0.000 & 0.000 & \\
\hline$a_{\pi}^{\pi, u n c}$ & & & & $-0.111 * * *$ \\
\hline$a_{\pi}^{y, u n c}$ & & & & $0.002 * * *$ \\
\hline$a_{y}$ & & & & \\
\hline$a_{y}^{u n c}$ & $0.795 * * *$ & $1.717 * * *$ & $1.549 * * *$ & $1.509 * * *$ \\
\hline$a_{y}^{y, u n c}$ & & 0.001 & $0.001 * *$ & $-0.015 * * *$ \\
\hline$a_{y}^{\pi, u n c}$ & & & & -0.001 \\
\hline J-stats & $15.40(\mathrm{p}=0.65)$ & $5.79(\mathrm{p}=0.44)$ & $4.62(\mathrm{p}=0.70)$ & $4.41(\mathrm{p}=0.98)$ \\
\hline
\end{tabular}

Notes: The weight matrix is Heteroskedasticity- and autocorrelation-consistent. Standard errors robust to autocorrelation and heteroskedasticity. ${ }^{*}, * *, * * *$ denotes significance at 10, 5 and 1 level. J-stats refers to the Hansen's J statistics. 
Table 7: Taylor rule estimates with real time data - UK

\begin{tabular}{|c|c|c|c|c|}
\hline & \multirow[t]{2}{*}{ Taylor rule } & \multicolumn{3}{|c|}{ Taylor rule with uncertainty } \\
\hline & & (i) & (ii) & (iii) \\
\hline$a_{0}$ & $4.451 * * *$ & $4.124 * * *$ & $4.456 * * *$ & $4.962 * * *$ \\
\hline$\gamma_{t}$ & $0.923 * * *$ & $0.921 * * *$ & $0.936 * * *$ & $0.899 * * *$ \\
\hline$\gamma_{t}^{u n c}$ & & 0.000 & & \\
\hline$a_{\pi}$ & $1.546 * * *$ & $2.064 * *$ & $3.205 * *$ & $1.381 * * *$ \\
\hline$a_{\pi}^{u n c}$ & & 0.018 & 0.014 & \\
\hline$a_{\pi}^{\pi, u n c}$ & & & & -0.005 \\
\hline$a_{\pi}^{y, u n c}$ & & & & $0.167 * * *$ \\
\hline$a_{y}$ & $1.216 * * *$ & 0.126 & -5.151 & $0.813 * * *$ \\
\hline$a_{y}^{u n c}$ & & $-0.024 *$ & -0.146 & \\
\hline$a_{y}^{y, u n c}$ & & & & $-0.094 * * *$ \\
\hline$a_{y}^{\pi, u n c}$ & & & & 0.011 \\
\hline J-stats & $15.76(\mathrm{p}=0.20)$ & $4.41(\mathrm{p}=0.98)$ & $1.94(\mathrm{p}=0.99)$ & $4.36(\mathrm{p}=0.82)$ \\
\hline
\end{tabular}

Notes: The weight matrix is Heteroskedasticity- and autocorrelation-consistent. Standard errors robust to autocorrelation and heteroskedasticity. $*, * *, * * *$ denotes significance at 10, 5 and 1 level. J-stats refers to the Hansen's J statistics. 